\title{
BMJ Open Associations between multimorbidity and glycaemia (HbA1c) in people with type 2 diabetes: cross-sectional study in Australian general practice
}

\author{
Jason I Chiang (D) , ${ }^{1}$ John Furler (D) , ${ }^{1}$ Frances Mair, ${ }^{2}$ Bhautesh D Jani, ${ }^{2}$ \\ Barbara I Nicholl, ${ }^{2}$ Sharmala Thuraisingam, ${ }^{1}$ Jo-Anne Manski-Nankervis
}

To cite: Chiang JI, Furler J, Mair F, et al. Associations between multimorbidity and glycaemia $(\mathrm{HbA1c})$ in people with type 2 diabetes: crosssectional study in Australian general practice. BMJ Open 2020;10:e039625. doi:10.1136/ bmjopen-2020-039625

- Prepublication history and additional materials for this paper is available online. To view these files, please visit the journal online (http://dx.doi org/10.1136/bmjopen-2020039625).

Received 21 April 2020 Revised 18 September 2020 Accepted 26 October 2020

Check for updates

(C) Author(s) (or their employer(s)) 2020. Re-use permitted under CC BY-NC. No commercial re-use. See rights and permissions. Published by BMJ.

${ }^{1}$ Department of General Practice and Primary Health Care, University of Melbourne, Melbourne, Victoria, Australia

${ }^{2}$ General Practice and Primary Care, University of Glasgow, Glasgow, UK

Correspondence to

Jason I Chiang;

jason.chiang@unimelb.edu.au

\section{ABSTRACT}

Objectives To explore the prevalence of multimorbidity as well as individual and combinations of long-term conditions (LTCS) in people with type 2 diabetes (T2D) attending Australian general practice, using electronic health record (EHR) data. We also examine the association between multimorbidity condition count (total/concordant(T2D related)/discordant(unrelated)) and glycaemia (glycated haemoglobin, HbA1c).

Design Cross-sectional study.

Setting Australian general practice.

Participants 69718 people with T2D with a general practice encounter between 2013 and 2015 captured in the Medicinelnsight database (EHR Data from 557 general practices and $>3.8$ million Australian patients).

Primary and secondary outcome measures Prevalence of multimorbidity, individual and combinations of LTCs. Multivariable linear regression models used to examine associations between multimorbidity counts and $\mathrm{HbA} 1 \mathrm{c}$ (\%).

Results Mean (SD) age 66.42 (12.70) years, 46.1\% female and mean (SD) HbA1c 7.1 (1.4)\%. More than 90\% of participants with $\mathrm{T} 2 \mathrm{D}$ were living with multimorbidity. Discordant conditions were more prevalent (83.4\%) than concordant conditions (69.9\%). The three most prevalent discordant conditions were: painful conditions (55.4\%), dyspepsia (31.6\%) and depression (22.8\%). The three most prevalent concordant conditions were hypertension (61.4\%), coronary heart disease $(17.1 \%)$ and chronic kidney disease (8.5\%). The three most common combinations of conditions were: painful conditions and hypertension (38.8\%), painful conditions and dyspepsia (23.1\%) and hypertension and dyspepsia (22.7\%). We found no associations between any multimorbidity counts (total, concordant and discordant) or combinations and HbA1c.

Conclusions Multimorbidity was common in our cohort of people with T2D attending Australian general practice, but was not associated with glycaemia. Although we did not explore mortality in this study, our results suggest that the increased mortality in those with multimorbidity and T2D observed in other studies may not be linked to glycaemia. Interestingly, discordant conditions were more prevalent than concordant conditions with painful conditions being the second most common comorbidity. Better understanding of the implications of different patterns of

\section{Strengths and limitations of this study}

- This is the first study to assess the associations between total, concordant and discordant multimorbidity counts and multimorbidity combinations, and glycated haemoglobin ( $\mathrm{HbA1c}$ ) in people with type 2 diabetes (T2D) in Australian general practice.

- The study utilised a large, national, routinely collected real world general practice dataset from 557 Australian general practices.

- We recognise the limitation of a cross-sectional study design where we did not consider the changes in long-term conditions (LTCs) and HbA1c over time, and the duration of LTCs in addition to T2D.

- The study relies on data entered into the electronic health records and therefore there is a possibility in under-reporting of conditions as a result of nonrecording of diagnoses and the way each long-term condition is recorded which is dependent on the clinicians' recording practices.

multimorbidity in people with T2D will allow more effective tailored care.

\section{BACKGROUND}

Type 2 diabetes (T2D) is recognised as a leading health priority associated with increased risk for premature mortality and is a global economic burden. ${ }^{1}$ Multimorbidity is the co-occurrence of two or more long-term conditions (LTCs) in an individual, ${ }^{23}$ which is the norm in T2D. It has been estimated that approximately $85 \%$ of those living with T2D have at least one other LTC. ${ }^{4}$ Multimorbidity amplifies the complex management of T2D including the challenges in managing higher treatment burden due to complicated self-management requirements as a result of having multiple LTCs $^{5}$ and has been associated with increased mortality. ${ }^{6}$ Multimorbidity in those with T2D could result in reduced adherence to complex therapeutic regimens 
and poorer outcomes including suboptimal glycaemic management, ${ }^{7-9}$ which may underpin poor outcomes. Glycated haemoglobin (HbA1c) is an important clinical measure to consider in T2D and glycaemic management is a key component of clinical guidelines for people with T2D.

HbA1c has been used to established glycaemic targets and measure efficacy of T2D management and treatment. It is evident that reducing HbA1c and avoiding hyperglycaemia results in clinical benefits including reduced microvascular and cardiovascular complications. ${ }^{9-12}$ Indeed, for every $1 \%$ increase in HbAlc, there is a $21 \%$ increase in risk of serious and costly complications. $^{13}$

A recent systematic review examined all existing studies that explored associations between multimorbidity and any glycaemic outcomes, including $\mathrm{HbAlc}$, in people with T2D. ${ }^{14}{ }^{15}$ It identified 14 cross-sectional studies that showed mixed associations between multimorbidity and HbAlc, however, none of the studies were conducted in an Australian setting or population. Despite the importance of examining the impact of multimorbidity in people with T2D, particularly its effect on glycaemia, currently, there is no universally accepted measure of multimorbidity. However, it has been suggested that multiple LTCs in people with T2D should be qualitatively assessed as concordant or discordant. ${ }^{8}$ Concordant conditions are those closely related to T2D that are more likely to be the focus of the same disease and management plan (eg, hypertension), whereas discordant conditions are not directly related in their pathophysiology or management (eg, depression and cancer).

While the association between multimorbidity and HbA1c in people with T2D has been studied to some extent, ${ }^{14}$ we do not have a good understanding of the different patterns of multimorbidity, including concordant and discordant conditions, and how they are associated with HbA1c in T2D in Australian general practice. The Academy of Medical Sciences has highlighted the importance of increasing understanding of different patterns of multimorbidity internationally, including identifying common clusters of LTCs. ${ }^{16}$ A study has examined the prevalence of combinations of two and three LTCs in Australian general practice though not in people with T2D. ${ }^{17}$ One of the guiding principles for multimorbidity in the Royal Australian College of General Practitioner (RACGP) guidelines for T2D management was to be aware of common comorbidities with T2D. ${ }^{18}$ We, therefore, explored the prevalence of multimorbidity including the prevalence of individual, concordant and discordant LTCs and condition combinations, in a cohort of people with T2D attending Australian general practice using MedicineInsight which routinely collects electronic health record (EHR) data. ${ }^{19}$ We also examined the associations between multimorbidity count (total, concordant and discordant) and HbA1c.

\section{METHODS}

\section{Study design and participants}

This cross-sectional study was conducted using data from MedicineInsight. This national database is managed by National Prescribing Service (NPS) MedicineWise and was established to support quality improvement in Australian general practice and postmarket surveillance of medicines. ${ }^{19}$ MedicineInsight extracts and collates longitudinal, deidentified patient health records, including demographics, encounters (excluding progress notes), diagnoses, prescriptions and pathology tests from general practice clinical information systems (CIS) Medical Director and Best Practice. Data extraction for our study was 1 September 2015, and included data from 557 Australian general practices, located in every Australian state and territory, and represented more than 3.8 million patient records. ${ }^{19}$

Patients aged $\geq 18$ years that had ever had a recorded diagnosis of T2D, marked as an active patient ${ }^{20}$ (defined as having at least three encounters recorded over a 2-year period [between 1 September of 2013 and 2015]) at 1 September 2015 were included in this study. This MedicineInsight dataset consisted of 105135 people with T2D during this time period. Of these, 35417 did not have HbAlc data recorded and were excluded from the study. We, therefore, analysed data from 69718 people.

\section{Procedures}

The included LTCs were based on previous published literature on multimorbidity. ${ }^{21}$ These consist of 43 individual LTCs where nine conditions were concordant with diabetes and the remainder discordant with diabetes (online supplemental table S1). Almost all LTCs were defined by composite definitions. We coded the conditions based on data entered in the reason for visit, reason for prescription or medical history fields and undertook an additional search to capture diagnoses recorded in free text. All codes were carefully reviewed by at least two expert academic general practitioners. In cases of uncertainty, a consensus was reached after discussion with a third expert. We included LTCs ever recorded in the MedicineInsight database. We created three new variables: the total number of LTCs, the number of concordant only conditions and number of discordant only conditions.

\section{Clinical outcome}

The outcome measure of interest was HbAlc (\%) and we used the most recently recorded HbAlc that has ever been in the participant's EHR, treated as a continuous variable. Results of HbA1c tests were identified using text searches on pathology test names (eg, HbAlc test may be recorded as HbAlc or glycated HbAlc or Haemoglobin A1c) and Logical Observation Identifiers Names and Codes, a code for a pathology test that is provided by pathology laboratories for our previous studies undertaken using this dataset. ${ }^{22-24}$ 


\section{Statistical analysis}

Descriptive statistics were used to summarise overall characteristics of the participants including age, sex, smoking status, $\mathrm{HbAlc}$, use of diabetes medication (number of non-insulin antidiabetic medications, insulin use only or both), and socioeconomic status measured by SocioEconomic Indexes for Areas (SEIFA) scores presented in deciles. ${ }^{25}$ The SEIFA scores for each participant postal code are calculated by summarising attributes of the population collected through Australia's national census, such as income, educational attainment, employment and occupation. These scores are grouped into deciles where decile one represents the most disadvantaged and decile 10 represents the least disadvantaged. The counts and proportions of LTCs concordant and discordant with diabetes were also summarised. Summaries include frequencies and percentages for categorical data, means and SD for normally distributed continuous data and medians and IQR for skewed continuous data. $\chi^{2}$ and t-tests were used to compare differences between people with T2D who had multiple LTCs and people with T2D only.

Multivariable mixed-effects linear regression models were used to examine the association between HbAlc and each of the multimorbidity counts (total; total of concordant conditions; total of discordant conditions) controlling for age, sex, SEIFA decile, smoking status and number of diabetes medications. Duration of diabetes was originally included in the adjusted model but was removed due to multicollinearity with age. The model without the inclusion of diabetes duration resulted in a better fit of the data with variance inflation factors reduced to within acceptable limits and improved stability.

In a secondary analysis, we selected the LTCs in our multimorbidity count that occur with a prevalence of more than $1 \%$ in this cohort. For each of the LTCs identified, multivariable mixed-effects linear regression models were used to examine the association with $\mathrm{HbAlc}$, adjusting for age, sex, SEIFA decile, smoking status and number of diabetes medication. Consistent with the RACGP guidelines for multimorbidity in people with T2D, we also selected the top 10 most prevalent LTCs and examined all possible combinations of two conditions and their association with HbA1c using multivariable mixed-effects linear regression models.

In all the regression models, we treated the confounding factors as fixed effects and the general practice as a random effect to allow for the correlation of HbAlc within each practice. All analyses were carried out using STATA V.15.1 (StataCorp).

\section{Sensitivity analysis}

In the sensitivity analysis, we categorised our study participants by the general treatment target of HbAlc (those with $\mathrm{HbAlc}>7 \%$ and $\leq 7 \%) .{ }^{26}$ We explored the association between HbA1c and each of the multimorbidity counts using multivariable mixed-effects linear regression models in each of the HbA1c groups. We adjusted for the same covariates as the main analysis described above.

\section{RESULTS}

In this cohort of 69718 people with T2D attending Australian general practice the mean (SD) age was 66.42 (12.70) and $46.1 \%$ were female. In our study, multimorbidity was present in $63326(90.8 \%)$. Table 1 describes the overall characteristics of our study participants and compares the characteristics between those with T2D and multimorbidity and those with T2D only. The characteristics of those with T2D and multimorbidity and those with T2D only were similar.

The prevalence of individual LTCs included in our multimorbidity total, concordant and discordant counts are shown in table 2. In our study cohort, 48733 (69.9\%) people had at least one concordant condition and 58151 (83.4\%) had at least one discordant condition in addition to T2D. The most prevalent concordant condition was hypertension $(61.4 \%)$ while painful conditions $(55.4 \%)$ was the most prevalent discordant condition.

Table 3 shows the mean difference in HbAlc between participants with different multimorbidity counts where participants with T2D only were the reference group. For all increasing counts of multimorbidity (total, concordant and discordant) there were no association with HbA1c.

In the sensitivity analysis, when we categorised the study participants into HbAlc of $>7 \%$ and $\leq 7 \%$ the results for the effect of all multimorbidity counts on HbA1c were similar to the main analysis, where there was no evidence to support any associations between multimorbidity counts and HbAlc (online supplemental table S2).

Table 4 shows the association between individual LTCs that had a prevalence of greater than $1 \%$ in our study population and HbAlc. All concordant conditions and 23 discordant conditions met this criterion. We did not find any associations between each of the individual LTCs (prevalence 1\%) and $\mathrm{HbAlc}$, with the exception of coronary heart disease.

Figure 1 shows the prevalence of all possible combinations of two conditions of the top 10 most prevalent conditions in our cohort. The most prevalent combinations were painful conditions and hypertension (38.8\%), painful conditions and dyspepsia (23.1\%), hypertension and dyspepsia (22.7\%), painful conditions and depression (15.8\%), and hypertension and depression (14.9\%).

Table 5 shows the association between combinations of two LTCs from the top 10 most prevalent conditions in our cohort and HbAlc. We found associations between slightly higher HbAlc and coronary heart disease in combination with hypertension, depression, anxiety and psoriasis/eczema. We did not find associations between any of the other combinations and HbAlc.

\section{DISCUSSION}

In this study, comprising of nearly 70000 people with T2D regularly attending Australian general practice, $90.8 \%$ of 
Table 1 Characteristics of participants with type 2 diabetes (T2D)

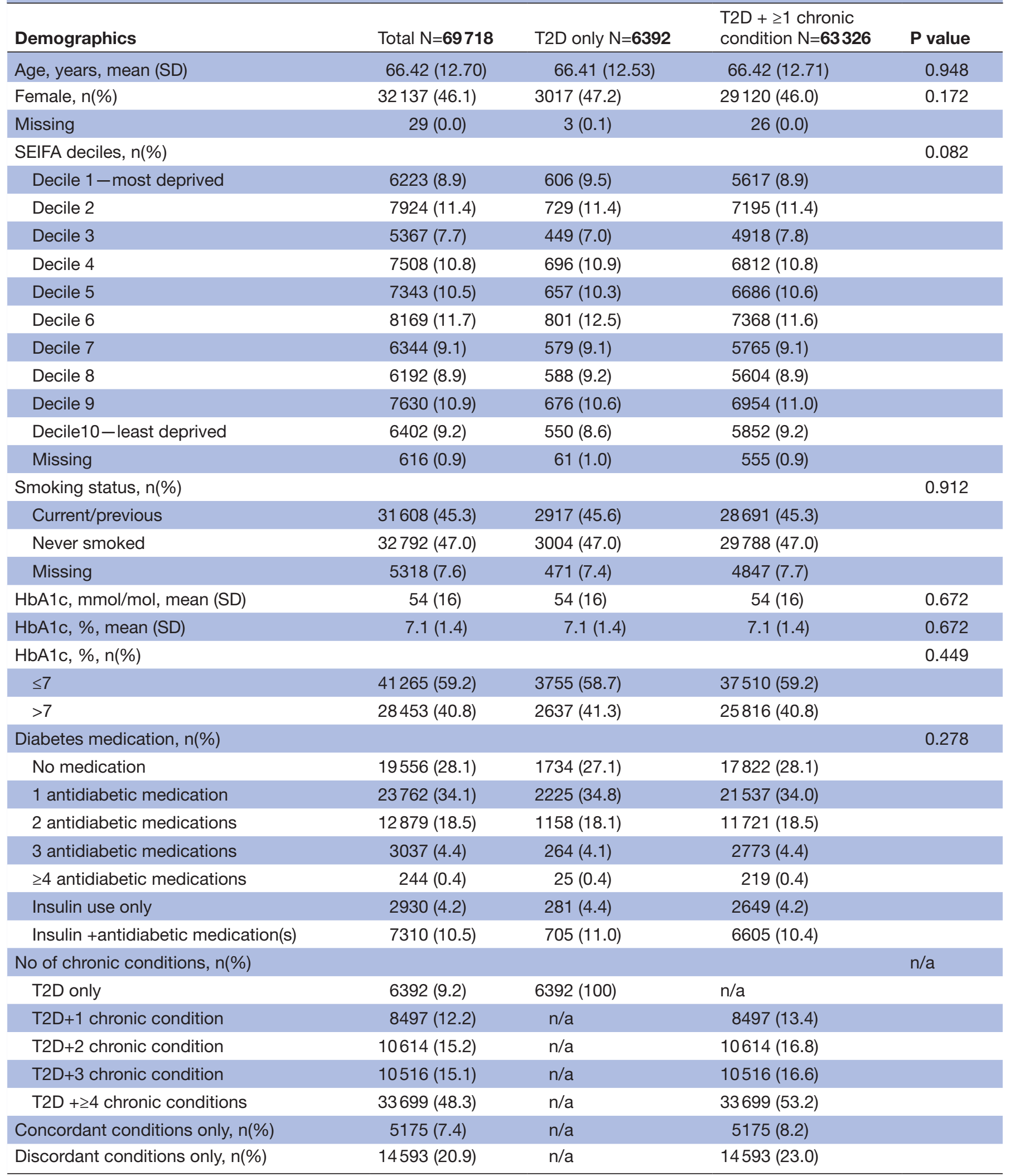

HbA1c, glycated haemoglobin; n/a, not applicable; SEIFA, Socio-Economic Indexes for Areas.

people were living with at least one other LTC in addition to T2D. Discordant conditions (such as painful conditions, dyspepsia, depression or psoriasis) were more prevalent $(83.4 \%)$ than concordant conditions $(69.9 \%)$. Our findings showed no evidence of an association between any counts of multimorbidity (total, concordant 
Table 2 Prevalence of individual multimorbid conditions in participants with type 2 diabetes

\begin{tabular}{lc}
\hline $\begin{array}{l}\text { Presence of chronic conditions } \\
\text { concordant with type 2 diabetes, } \mathbf{n ( \% )}\end{array}$ & $\mathbf{N}=69718$ \\
$\begin{array}{l}\text { At least one chronic condition } \\
\text { concordant with diabetes }\end{array}$ & $48733(69.9)$ \\
$\begin{array}{l}\text { Hypertension } \\
\text { Coronary heart disease }\end{array}$ & $42812(61.4)$ \\
\hline Chronic kidney disease & $11953(17.1)$ \\
\hline Atrial fibrillation & $5919(8.5)$ \\
\hline Stroke/TIA & $5318(7.3)$ \\
\hline Heart failure & $4730(6.8)$ \\
\hline Diabetic retinopathy & $4410(6.3)$ \\
\hline Peripheral vascular disease & $2266(3.3)$ \\
\hline $\begin{array}{l}\text { Diabetic neuropathy } \\
\text { Presence of chronic conditions } \\
\text { discordant with type 2 diabetes, } \mathbf{n ( \% )}\end{array}$ & $\mathbf{n}=697118$ \\
\hline
\end{tabular}

At least one chronic condition

discordant with diabetes

\begin{tabular}{lc|}
\hline Painful conditions & $38645(55.4)$ \\
\hline Dyspepsia & $22022(31.6)$ \\
\hline Depression & $15926(22.8)$ \\
\hline Anxiety & $14262(20.5)$ \\
\hline Psoriasis/eczema & $14037(20.1)$ \\
\hline Cancer & $12733(18.3)$ \\
\hline Asthma & $10276(14.7)$ \\
\hline Thyroid disorders & $7613(10.9)$ \\
\hline Diverticular disease & $6039(8.7)$ \\
\hline COPD & $5521(7.9)$ \\
\hline Constipation & $5162(7.4)$ \\
\hline Chronic liver disease & $4864(7.0)$ \\
\hline Osteoporosis & $4567(6.6)$ \\
\hline Glaucoma & $3102(4.5)$ \\
\hline Migraine & $2643(3.8)$ \\
\hline Rheumatoid arthritis and other & $2622(3.8)$ \\
\hline connective tissue disorders & \\
\hline Dementia & $2247(3.2)$ \\
\hline Schizophrenia/bipolar disorder & $2198(3.2)$ \\
\hline Irritable bowel syndrome & $1540(2.2)$ \\
\hline Alcohol problems & $1447(2.1)$ \\
\hline Viral hepatitis & $815(1.2)$ \\
\hline Epilepsy & $754(1.1)$ \\
\hline Parkinson's disease & $628(0.9)$ \\
\hline Chronic sinusitis & $597(0.9)$ \\
\hline Meniere's disease & $520(0.8)$ \\
\hline Inflammatory bowel disease & $515(0.7)$ \\
\hline Polycystic ovary & $488(0.7)$ \\
\hline Other psychoactive substance misuse & $463(0.7)$ \\
\hline & \\
\hline
\end{tabular}

Continued

\begin{tabular}{ll} 
Table 2 Continued & \\
\hline Bronchiectasis & $448(0.6)$ \\
\hline Pernicious anaemia & $330(0.5)$ \\
Endometriosis & $280(0.4)$ \\
Chronic fatigue syndrome & $168(0.2)$ \\
Prostate disorders & $154(0.2)$ \\
Anorexia/bulimia & $148(0.2)$ \\
Multiple sclerosis & $114(0.2)$ \\
\hline
\end{tabular}

COPD, chronic obstructive pulmonary disease; TIA, transient ischaemic attack.

and discordant) and HbAlc. The presence of individual and combinations of LTCs in addition to T2D were not associated with $\mathrm{HbA1c}$, with the exception of coronary heart disease.

Our prevalence findings of multimorbidity add to existing literature where it has been estimated that approximately $85 \%$ of those living with T2D have at least one other LTC. ${ }^{4}$ The prevalence of individual LTCs identified in our study align with a recent study that explored multimorbidity in people with T2D across the UK and Taiwan. ${ }^{6}$ This is in spite of the study examining community cohorts of people with T2D rather than people attending general practice. This confirms how commonly people are burdened by multimorbidity and that that this is likely to impact on the already complex nature of T2D management. Currently, the Royal Australia College of General Practitioners (RACGP) guidelines for T2D acknowledge that clinical guidance regarding the management of comorbid conditions is currently lacking or sparse. ${ }^{18}$ However, one guiding principle was to be aware of common comorbidities with diabetes. Our findings regarding the most common LTCs associated, either singly or in combination, with T2D have direct implications for this. We showed that for concordant conditions, hypertension was the most common condition, and following that was coronary artery disease. It should be noted that the treatment and prevention of these conditions with the exception of atrial fibrillation and partially heart failure have been incorporated into the diabetes guidelines. ${ }^{18}$ However, importantly, discordant conditions were more prevalent than concordant conditions in our study, where painful conditions was the most common comorbidity. Although the RACGP guideline recommends that clinicians should be aware of commonly occurring conditions, another guiding principle is to set treatment priorities with the patient. ${ }^{18}$ It is important to focus on outcomes and co-occurring conditions that matter most to the individual because shared decision making is vital to ensure care is tailored to the individual. ${ }^{827-29}$ Given how common painful conditions are, patients may prioritise therapeutic interventions differently, for example pain relief being considered above diabetes management. 
Table 3 Multivariable linear regression model: relationship between $\mathrm{HbA} 1 \mathrm{c}(\%)$ and multimorbidity in participants with type 2 diabetes

\begin{tabular}{|c|c|c|c|c|c|c|}
\hline \multirow[b]{2}{*}{ Predictor variables } & \multicolumn{3}{|l|}{ Non-adjusted } & \multicolumn{3}{|l|}{ Adjusted $^{*}$} \\
\hline & $\begin{array}{l}\text { Mean } \\
\text { difference in } \\
\text { HbA1c (SE) }\end{array}$ & $95 \% \mathbf{C l}$ & $P$ value & $\begin{array}{l}\text { Mean } \\
\text { difference in } \\
\text { HbA1c (SE) }\end{array}$ & $95 \% \mathbf{C l}$ & P value \\
\hline \multicolumn{7}{|c|}{ Categories of diabetes and multimorbidities } \\
\hline \multicolumn{7}{|c|}{ Diabetes present and no chronic conditions (reference) } \\
\hline $\begin{array}{l}\text { Diabetes present and one chronic } \\
\text { condition }\end{array}$ & $-0.01(0.02)$ & -0.05 to 0.04 & 0.757 & $-0.01(0.02)$ & -0.05 to 0.04 & 0.685 \\
\hline $\begin{array}{l}\text { Diabetes present and two chronic } \\
\text { conditions }\end{array}$ & $-0.02(0.02)$ & -0.07 to 0.02 & 0.348 & $-0.02(0.02)$ & -0.06 to 0.02 & 0.341 \\
\hline $\begin{array}{l}\text { Diabetes present and three chronic } \\
\text { conditions }\end{array}$ & $-0.01(0.02)$ & -0.06 to 0.03 & 0.549 & $0.00(0.02)$ & -0.04 to 0.04 & 0.968 \\
\hline $\begin{array}{l}\text { Diabetes present and four or more } \\
\text { chronic conditions }\end{array}$ & $0.00(0.02)$ & -0.04 to 0.04 & 0.912 & $-0.01(0.02)$ & -0.04 to 0.03 & 0.731 \\
\hline $\begin{array}{l}\text { Diabetes present and one concordant } \\
\text { condition }\end{array}$ & $0.01(0.01)$ & -0.02 to 0.03 & 0.701 & $0.00(0.01)$ & -0.02 to 0.03 & 0.799 \\
\hline $\begin{array}{l}\text { Diabetes present and two concordant } \\
\text { conditions }\end{array}$ & $0.02(0.02)$ & -0.01 to 0.05 & 0.250 & $0.02(0.02)$ & -0.01 to 0.05 & 0.150 \\
\hline $\begin{array}{l}\text { Diabetes present and three } \\
\text { concordant conditions }\end{array}$ & $0.00(0.02)$ & -0.04 to 0.05 & 0.947 & $-0.01(0.02)$ & -0.05 to 0.03 & 0.556 \\
\hline $\begin{array}{l}\text { Diabetes present and four or more } \\
\text { concordant conditions }\end{array}$ & $0.05(0.03)$ & -0.01 to 0.10 & 0.100 & $0.04(0.03)$ & -0.02 to 0.09 & 0.175 \\
\hline \multicolumn{7}{|c|}{ Categories of diabetes and discordant conditions } \\
\hline \multicolumn{7}{|c|}{ Diabetes present and no chronic conditions (reference) } \\
\hline
\end{tabular}

${ }^{*}$ Adjusting for age, sex, SEIFA, smoking status, and number of diabetes medication. All co-variates were treated as fixed effects and the general practice as a random effect to allow for the correlation of $\mathrm{HbA1c}$ within each practice.

HbA1c, glycated haemoglobin; SEIFA, Socio-Economic Indexes for Areas.

We also contribute to the understanding of patterns of multimorbidity in people with T2D through exploring the most common combinations of two LTCs. Our LTC combinations findings further confirms the significance of discordant conditions in T2D. We showed that painful conditions, dyspepsia, depression, psoriasis/eczema, anxiety, cancer and one concordant condition, hypertension, were present in the majority of the most common combinations. While managing concordant conditions, namely cardiovascular diseases, are important, it should not overshadow efforts to address discordant conditions in people with T2D.

Our results add to the findings of a recent systematic review which highlighted mixed associations between multimorbidity and HbAlc in T2D. ${ }^{14}$ It has been well established that achieving HbAlc targets is a key component of T2D management and clinical guidelines and is important in reducing downstream complications and risk of mortality. ${ }^{30}$ Our findings contrast with a recent study of diabetes and multimorbidity using data from UK Biobank and the Taiwan National Diabetes Care Management Programme which suggested that increasing total and discordant multimorbidity counts were associated with lower HbAlc and increased mortality in both datasets. ${ }^{6}$ Our findings show that coronary heart disease was associated with slightly higher HbAlc both when considered as an individual condition and in different combinations with hypertension, depression, anxiety and psoriasis/eczema. Although the degree of observed differences in HbAlc noted in our study (ranging from 
Table 4 Multivariable linear regression model: relationship between $\mathrm{HbA1c}(\%)$ and the presence of individual conditions (prevalence $>1 \%$ ) in participants with type 2 diabetes (T2D)

\begin{tabular}{|c|c|c|c|c|c|c|c|}
\hline \multirow[b]{2}{*}{ Predictor variables } & \multirow[b]{2}{*}{$\begin{array}{l}\text { Prevalence } \\
\mathrm{N}(\%)\end{array}$} & \multicolumn{3}{|l|}{ Non-adjusted } & \multicolumn{3}{|l|}{ Adjusted ${ }^{*}$} \\
\hline & & $\begin{array}{l}\text { Mean difference } \\
\text { in HbA1c (SE) }\end{array}$ & $95 \% \mathrm{Cl}$ & $P$ value & $\begin{array}{l}\text { Mean difference } \\
\text { in HbA1c (SE) }\end{array}$ & $95 \% \mathrm{Cl}$ & $P$ value \\
\hline \multicolumn{8}{|l|}{ Concordant conditions } \\
\hline \multicolumn{8}{|l|}{ T2D only (reference) } \\
\hline Hypertension & $42812(61.4)$ & $0.01(0.01)$ & -0.01 to 0.03 & 0.364 & $0.01(0.01)$ & -0.01 to 0.03 & 0.336 \\
\hline $\begin{array}{l}\text { Coronary heart } \\
\text { disease }\end{array}$ & $11953(17.1)$ & $0.03(0.02)$ & 0.00 to 0.06 & 0.022 & $0.03(0.01)$ & 0.00 to 0.05 & 0.040 \\
\hline $\begin{array}{l}\text { Chronic kidney } \\
\text { disease }\end{array}$ & $5919(8.5)$ & $0.01(0.02)$ & -0.03 to 0.05 & 0.745 & $-0.01(0.02)$ & -0.05 to 0.02 & 0.456 \\
\hline Atrial fibrillation & $5318(7.3)$ & $0.01(0.02)$ & -0.03 to 0.05 & 0.567 & $0.00(0.02)$ & -0.04 to 0.04 & 0.907 \\
\hline Stroke/TIA & $4730(6.8)$ & $-0.01(0.02)$ & -0.05 to 0.03 & 0.692 & $0.00(0.02)$ & -0.42 to 0.04 & 0.919 \\
\hline Heart failure & $4410(6.3)$ & $0.02(0.02)$ & -0.02 to 0.07 & 0.333 & $0.01(0.02)$ & -0.03 to 0.05 & 0.622 \\
\hline Diabetic retinopathy & 2266 (3.3) & $-0.02(0.03)$ & -0.08 to 0.04 & 0.547 & $0.00(0.03)$ & -0.06 to 0.06 & 0.996 \\
\hline $\begin{array}{l}\text { Peripheral vascular } \\
\text { disease }\end{array}$ & $1945(2.8)$ & $0.05(0.03)$ & -0.02 to 0.11 & 0.151 & $0.02(0.03)$ & -0.05 to 0.08 & 0.509 \\
\hline Diabetic neuropathy & $1117(1.6)$ & $-0.01(0.04)$ & -0.10 to 0.07 & 0.763 & $0.01(0.04)$ & -0.07 to 0.09 & 0.892 \\
\hline \multicolumn{8}{|l|}{ Discordant conditions } \\
\hline \multicolumn{8}{|l|}{ T2D only (reference) } \\
\hline Painful conditions & 38645 (55.4) & $0.01(0.01)$ & -0.04 to 0.01 & 0.211 & $-0.02(0.01)$ & -0.04 to 0.00 & 0.122 \\
\hline Dyspepsia & $22022(31.6)$ & $0.00(0.01)$ & -0.02 to 0.02 & 0.954 & $0.00(0.01)$ & -0.02 to 0.03 & 0.746 \\
\hline Depression & $15926(22.8)$ & $0.00(0.01)$ & -0.03 to 0.80 & 0.801 & $-0.01(0.01)$ & -0.03 to 0.02 & 0.600 \\
\hline Anxiety & $14262(20.5)$ & $0.00(0.01)$ & -0.02 to 0.03 & 0.772 & $-0.01(0.01)$ & -0.03 to 0.02 & 0.621 \\
\hline Psoriasis/eczema & $14037(20.1)$ & $0.02(0.01)$ & -0.01 to 0.04 & 0.193 & $0.02(0.01)$ & -0.01 to 0.04 & 0.130 \\
\hline Cancer & $12733(18.3)$ & $0.01(0.01)$ & -0.01 to 0.04 & 0.319 & $0.00(0.01)$ & -0.02 to 0.03 & 0.704 \\
\hline Asthma & $10276(14.7)$ & $-0.01(0.02)$ & -0.04 to 0.02 & 0.412 & $-0.02(0.01)$ & -0.05 to 0.01 & 0.219 \\
\hline Thyroid disorders & $7613(10.9)$ & $0.02(0.02)$ & -0.02 to 0.05 & 0.309 & $0.00(0.02)$ & -0.03 to 0.03 & 0.961 \\
\hline Diverticular disease & $6039(8.7)$ & $0.02(0.19)$ & -0.02 to 0.06 & 0.279 & $0.02(0.02)$ & -0.02 to 0.05 & 0.366 \\
\hline COPD & $5521(7.9)$ & $0.02(0.02)$ & -0.02 to 0.06 & 0.315 & $0.02(0.02)$ & -0.02 to 0.06 & 0.273 \\
\hline Constipation & $5162(7.4)$ & $0.02(0.02)$ & -0.02 to 0.06 & 0.339 & $0.01(0.02)$ & -0.03 to 0.05 & 0.524 \\
\hline $\begin{array}{l}\text { Chronic liver } \\
\text { disease }\end{array}$ & $4864(7.0)$ & $0.03(0.02)$ & -0.01 to 0.08 & 0.129 & $0.02(0.02)$ & -0.02 to 0.06 & 0.222 \\
\hline Osteoporosis & $4567(6.6)$ & $0.00(0.02)$ & -0.04 to 0.05 & 0.882 & $0.01(0.02)$ & -0.03 to 0.05 & 0.761 \\
\hline Glaucoma & $3102(4.5)$ & $0.05(0.03)$ & 0.00 to 0.11 & 0.038 & $0.03(0.02)$ & -0.02 to 0.08 & 0.235 \\
\hline $\begin{array}{l}\text { Rheumatoid } \\
\text { arthritis and other } \\
\text { connective tissue } \\
\text { disorders }\end{array}$ & $2643(3.8)$ & $-0.01(0.03)$ & -0.06 to 0.05 & 0.8 & $0.01(0.03)$ & -0.04 to 0.07 & 0.597 \\
\hline Migraine & $2622(3.8)$ & $-0.03(0.03)$ & -0.09 to 0.03 & 0.305 & $-0.01(0.03)$ & -0.07 to 0.04 & 0.575 \\
\hline Dementia & $2247(3.2)$ & $0.05(0.03)$ & -0.01 to 0.11 & 0.09 & $0.03(0.03)$ & -0.02 to 0.09 & 0.255 \\
\hline $\begin{array}{l}\text { Schizophrenia/ } \\
\text { bipolar disorder }\end{array}$ & $2198(3.2)$ & $-0.01(0.03)$ & -0.08 to 0.05 & 0.655 & $-0.01(0.03)$ & -0.07 to 0.05 & 0.694 \\
\hline $\begin{array}{l}\text { Irritable bowel } \\
\text { syndrome }\end{array}$ & $1540(2.2)$ & $-0.01(0.04)$ & -0.08 to 0.06 & 0.756 & $-0.01(0.03)$ & -0.08 to 0.05 & 0.676 \\
\hline Alcohol problem & $1447(2.1)$ & $0.00(0.04)$ & -0.07 to 0.08 & 0.96 & $0.00(0.04)$ & -0.07 to 0.07 & 0.974 \\
\hline Viral hepatitis & 815 (1.2) & $0.02(0.05)$ & -0.08 to 0.12 & 0.689 & $0.04(0.05)$ & -0.05 to 0.13 & 0.393 \\
\hline Epilepsy & $754(1.1)$ & $0.09(0.05)$ & -0.02 to 0.19 & 0.108 & $0.08(0.05)$ & -0.01 to 0.18 & 0.082 \\
\hline
\end{tabular}

*Adjusting for age, sex, SEIFA, smoking status, and number of diabetes medication. All covariates were treated as fixed effects and the general practice as a random effect to allow for the correlation of $\mathrm{HbA} 1 \mathrm{c}$ within each practice.

COPD, chronic obstructive pulmonary disease; HbA1c, glycated haemoglobin; TIA, transient ischaemic attack. 


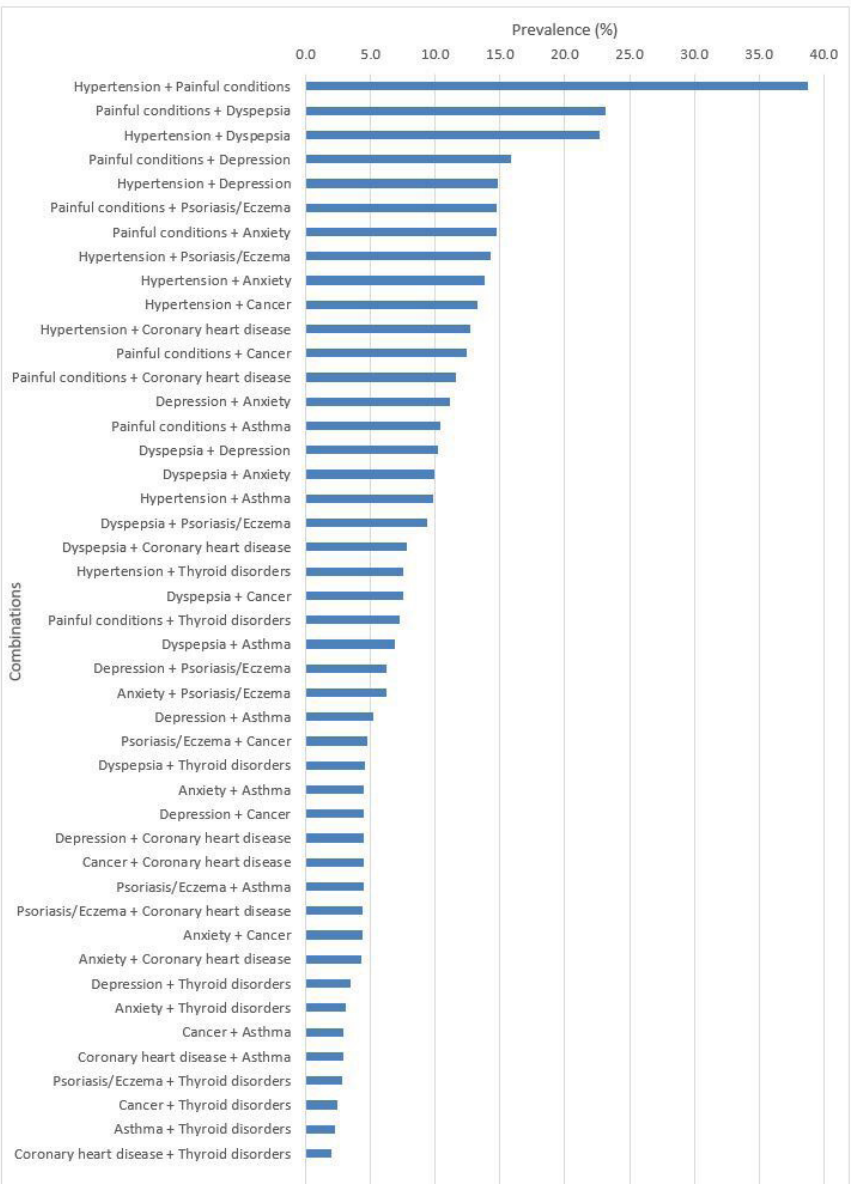

Figure 1 The presence of combinations of top 10 most prevalent conditions in participants with type 2 diabetes.

$0.03 \%$ to $0.08 \%$ ) and the recent UK and Taiwan study are very small and are not likely to be clinically significant despite being statistically significant. Our findings could possibly be linked to the higher healthcare utilisation $^{31}$ and better quality of care ${ }^{32}$ seen in people with LTCs, hence leading to more opportunities for clinical interventions leading to achieving HbAlc targets. This is further highlighted by our study cohort being relatively healthy with good glycaemic control (mean (SD) HbAlc $7.1(1.4) \%$ ), similar to the Australian general treatment target of $7 \% .^{26}$ Moreover, $28 \%$ of our study cohort was not on any diabetes medication further highlighting our generally healthy cohort of participants with T2D.

To the best of our knowledge, this is the first study to assess the effects of total, concordant and discordant multimorbidity counts on HbA1c in people with T2D in Australian general practice. The strength of the study includes using a large, national, routinely collected real world general practice dataset from 557 Australian general practices. We recognise the limitation of a cross-sectional study design where we did not consider the temporality of LTCs and HbAlc, and the duration of LTCs in addition to diabetes. Furthermore, when coding for LTCs we did not test inter-observer reliability. A limitation to note is that a relatively high number of participants were excluded from the study as they didn't have recorded HbAlc, and these participants may not be similar to those with recorded HbA1c. HbA1c was measured at various sites meaning possible variations due to measurement error at different sites could have affected the results of the study. We only included active patients defined as having at least three encounters recorded over a 2-year period and this could be a potential limitation where those excluded may have differences in baseline characteristics. We also did not conduct a sample size calculation in this retrospective observational study. As this was a dataset using routinely collected real world clinical data, a limitation of our study is that some important lifestyle variables such as physical activity were not available to be included in the analyses. Another limitation of the study is that the quality of MedicineInsight data is dependent on the accuracy and completeness of data recorded in general practice CISs, in fields that can be extracted or in a useable format. To improve the quality of the data, selection criteria for both patients and practices, and extensive data cleaning procedures are applied. ${ }^{19}$ For privacy reasons, MedicineInsight does not include data from progress notes, which may contain further clinical information. As such, this may result in underestimating the number of conditions experienced by people with T2D. In 2018, MedicineInsight published a report ${ }^{33}$ comparing their dataset in terms of the prevalence of LTCs captured to the Australian Bureau of Statistics (ABS) data, which is based on self-report, ${ }^{4}$ and data from the Bettering the Evaluation and Care of Health (BEACH) study, which is prospectively collected by general practitioners recording patient encounters on structured paper-based recording sheets. ${ }^{34}$ It is reported that the prevalence of chronic conditions in the MedicineInsight data align with ABS data or are slightly higher. When compared with data from the BEACH study, the MedicineInsight conditions, rates per 100 encounters were slightly lower. This may be the case because conditions that have been previously entered into EHR might not be re-entered by the clinicians into the relevant CIS fields used for analysis (reason for visit, reason for prescription or medical history fields), or data may be entered into the progress notes (which are not accessible to MedicineInsight). Furthermore, in the BEACH study, general practitioners were asked to provide complete information on structured paper-based recording sheets for a given encounter. Despite our efforts to compensate for the challenges of the MedicineInsight dataset by using a panel of expert academic general practitioners coding for conditions in multiple fields with additional searches in free text fields there is still a possibility in under-reporting of conditions as a result of non-recording of diagnoses and the way each LTC is recorded which is dependent on the clinicians' recording practices. Furthermore, it is possible that some patients captured in the dataset may have performed chronic disease screening elsewhere because in Australia, people are free to attend other and multiple general practice clinics although the majority tend to stay with one practice. Despite this, the prevalence 
Table 5 Multivariable linear regression model: relationship between $\mathrm{HbA} 1 \mathrm{c}(\%)$ and the presence of combinations of top 10 most prevalent conditions in participants with type 2 diabetes (T2D)

\begin{tabular}{|c|c|c|c|c|c|c|c|}
\hline \multirow[b]{2}{*}{ Predictor variables } & \multirow[b]{2}{*}{$\begin{array}{l}\text { Prevalence N } \\
(\%)\end{array}$} & \multicolumn{3}{|l|}{ Non-adjusted } & \multicolumn{3}{|l|}{ Adjusted $^{*}$} \\
\hline & & $\begin{array}{l}\text { Mean } \\
\text { difference in } \\
\text { HbA1c (SE) }\end{array}$ & $95 \% \mathbf{C l}$ & $P$ value & $\begin{array}{l}\text { Mean } \\
\text { difference in } \\
\text { HbA1c (SE) }\end{array}$ & $95 \% \mathbf{C l}$ & $P$ value \\
\hline \multicolumn{8}{|l|}{ Concordant conditions } \\
\hline \multicolumn{8}{|l|}{ T2D only (reference) } \\
\hline Hypertension+painful conditions & 27063 (38.8) & $-0.01(0.01)$ & -0.03 to 0.02 & 0.615 & $-0.01(0.01)$ & -0.03 to 0.01 & 0.399 \\
\hline Hypertension+dyspepsia & $15827(22.7)$ & $0.01(0.01)$ & -0.02 to 0.03 & 0.502 & $0.01(0.01)$ & -0.01 to 0.03 & 0.413 \\
\hline Painful conditions+depression & $11046(15.8)$ & $0.00(0.01)$ & -0.03 to 0.03 & 0.907 & $-0.01(0.01)$ & -0.03 to 0.02 & 0.675 \\
\hline Hypertension+depression & $10369(14.9)$ & $0.00(0.02)$ & -0.03 to 0.03 & 0.791 & $0.01(0.01)$ & -0.03 to 0.02 & 0.693 \\
\hline $\begin{array}{l}\text { Painful conditions+psoriasis/ } \\
\text { eczema }\end{array}$ & $10297(14.8)$ & $0.01(0.02)$ & -0.02 to 0.04 & 0.494 & $0.01(0.01)$ & -0.02 to 0.04 & 0.630 \\
\hline Hypertension+cancer & $9268(13.3)$ & $0.02(0.02)$ & -0.01 to 0.05 & 0.154 & $0.01(0.02)$ & -0.01 to 0.04 & 0.443 \\
\hline $\begin{array}{l}\text { Hypertension+coronary heart } \\
\text { disease }\end{array}$ & $8853(12.7)$ & $0.03(0.02)$ & 0.00 to 0.06 & 0.050 & $0.03(0.02)$ & 0.00 to 0.06 & 0.025 \\
\hline Painful conditions+cancer & $8645(12.4)$ & $0.02(0.02)$ & -0.02 to 0.05 & 0.299 & $0.01(0.02)$ & -0.02 to 0.04 & 0.702 \\
\hline $\begin{array}{l}\text { Painful conditions+coronary heart } \\
\text { disease }\end{array}$ & 8066 (11.6) & $0.02(0.02)$ & -0.01 to 0.06 & 0.191 & $0.02(0.02)$ & -0.01 to 0.05 & 0.260 \\
\hline Depression+anxiety & $7778(11.2)$ & $-0.01(0.02)$ & -0.04 to 0.03 & 0.692 & $-0.02(0.02)$ & -0.05 to 0.01 & 0.184 \\
\hline Painful conditions+asthma & $7213(10.4)$ & $-0.02(0.02)$ & -0.06 to 0.01 & 0.256 & $-0.03(0.02)$ & -0.07 to 0.00 & 0.048 \\
\hline Dyspepsia+depression & $7139(10.2)$ & $0.01(0.02)$ & -0.02 to 0.05 & 0.450 & $0.01(0.02)$ & -0.02 to 0.05 & 0.386 \\
\hline Dyspepsia+anxiety & 6927 (9.9) & $0.02(0.02)$ & -0.01 to 0.06 & 0.282 & $0.01(0.02)$ & -0.02 to 0.05 & 0.446 \\
\hline $\begin{array}{l}\text { Painful conditions+thyroid } \\
\text { disorders }\end{array}$ & $5046(7.2)$ & $0.00(0.02)$ & -0.04 to 0.04 & 0.953 & $-0.02(0.02)$ & -0.06 to 0.02 & 0.403 \\
\hline Dyspepsia+asthma & $4780(6.9)$ & $-0.01(0.02)$ & -0.06 to 0.03 & 0.533 & $-0.02(0.02)$ & -0.06 to 0.02 & 0.318 \\
\hline Depression+psoriasis/eczema & $4363(6.3)$ & $-0.01(0.02)$ & -0.05 to 0.04 & 0.800 & $-0.01(0.02)$ & -0.06 to 0.03 & 0.498 \\
\hline Anxiety+psoriasis/eczema & $4343(6.2)$ & $0.00(0.02)$ & -0.04 to 0.04 & 0.889 & $0.00(0.02)$ & -0.05 to 0.04 & 0.839 \\
\hline Depression+asthma & $3610(5.2)$ & $-0.02(0.02)$ & -0.07 to 0.03 & 0.477 & $-0.03(0.02)$ & -0.08 to 0.01 & 0.173 \\
\hline Psoriasis/eczema+cancer & $3293(4.7)$ & $0.04(0.03)$ & -0.01 to 0.09 & 0.117 & $0.03(0.02)$ & -0.02 to 0.07 & 0.275 \\
\hline Dyspepsia+thyroid disorders & $3193(4.6)$ & $0.05(0.03)$ & 0.00 to 0.10 & 0.068 & $0.03(0.02)$ & -0.02 to 0.07 & 0.268 \\
\hline Anxiety+asthma & $3144(4.5)$ & $-0.04(0.03)$ & -0.09 to 0.15 & 0.169 & $-0.05(0.02)$ & -0.10 to 0.00 & 0.044 \\
\hline Depression+cancer & $3126(4.5)$ & $0.03(0.03)$ & -0.02 to 0.09 & 0.206 & $0.01(0.02)$ & -0.04 to 0.06 & 0.721 \\
\hline $\begin{array}{l}\text { Depression+coronary heart } \\
\text { disease }\end{array}$ & $3115(4.5)$ & $0.08(0.03)$ & 0.03 to 0.14 & 0.001 & $0.08(0.02)$ & 0.03 to 0.12 & 0.003 \\
\hline Cancer+coronary heart disease & $3106(4.5)$ & $0.06(0.03)$ & 0.01 to 0.11 & 0.027 & $0.05(0.02)$ & 0.00 to 0.10 & 0.059 \\
\hline Psoriasis/eczema+asthma & $3103(4.5)$ & $-0.03(0.03)$ & -0.09 to 0.02 & 0.203 & $-0.04(0.02)$ & -0.08 to 0.01 & 0.147 \\
\hline $\begin{array}{l}\text { Psoriasis/eczema+coronary heart } \\
\text { disease }\end{array}$ & $3059(4.4)$ & $0.06(0.03)$ & 0.01 to 0.11 & 0.031 & $0.05(0.00)$ & 0.00 to 0.10 & 0.037 \\
\hline Anxiety+cancer & $3057(4.4)$ & $0.06(0.03)$ & 0.01 to 0.11 & 0.026 & $0.04(0.02)$ & -0.01 to 0.09 & 0.130 \\
\hline Anxiety+coronary heart disease & 2977 (4.3) & $0.08(0.03)$ & 0.02 to 0.13 & 0.005 & $0.06(0.03)$ & 0.01 to 0.11 & 0.014 \\
\hline
\end{tabular}


Table 5 Continued

\begin{tabular}{|c|c|c|c|c|c|c|c|}
\hline \multirow[b]{2}{*}{ Predictor variables } & \multirow[b]{2}{*}{$\begin{array}{l}\text { Prevalence N } \\
(\%)\end{array}$} & \multicolumn{3}{|l|}{ Non-adjusted } & \multicolumn{3}{|l|}{ Adjusted* $^{*}$} \\
\hline & & $\begin{array}{l}\text { Mean } \\
\text { difference in } \\
\text { HbA1c (SE) }\end{array}$ & $95 \% \mathrm{Cl}$ & $P$ value & $\begin{array}{l}\text { Mean } \\
\text { difference in } \\
\text { HbA1c (SE) }\end{array}$ & $95 \% \mathbf{C I}$ & $P$ value \\
\hline Depression+thyroid disorders & $2396(3.4)$ & $0.01(0.03)$ & -0.05 to 0.07 & 0.681 & $-0.01(0.03)$ & -0.06 to 0.05 & 0.815 \\
\hline Anxiety+thyroid disorders & $2152(3.1)$ & $0.02(0.03)$ & -0.04 to 0.08 & 0.533 & $-0.01(0.03)$ & -0.06 to 0.05 & 0.847 \\
\hline Cancer+asthma & $2040(2.9)$ & $-0.02(0.03)$ & -0.08 to 0.04 & 0.516 & $-0.03(0.03)$ & -0.08 to 0.04 & 0.496 \\
\hline $\begin{array}{l}\text { Psoriasis/eczema+thyroid } \\
\text { disorders }\end{array}$ & $1986(2.9)$ & $0.04(0.03)$ & -0.02 to 0.11 & 0.215 & $0.04(0.03)$ & -0.02 to 0.10 & 0.250 \\
\hline Cancer+thyroid disorders & $1720(2.5)$ & $0.04(0.04)$ & -0.03 to 0.11 & 0.241 & $0.01(0.03)$ & -0.05 to 0.08 & 0.712 \\
\hline Asthma+thyroid disorders & $1551(2.2)$ & $0.00(0.04)$ & -0.07 to 0.07 & 0.963 & $0.00(0.03)$ & -0.07 to 0.07 & 0.972 \\
\hline $\begin{array}{l}\text { Coronary heart disease+thyroid } \\
\text { disorders }\end{array}$ & $1400(2.0)$ & $0.06(0.04)$ & -0.01 to 0.14 & 0.109 & $0.07(0.04)$ & 0.00 to 0.14 & 0.065 \\
\hline
\end{tabular}

*Adjusting for age, sex, SEIFA, smoking status, and number of diabetes medication. All covariates were treated as fixed effects and the general practice as a random effect to allow for the correlation of $\mathrm{HbA} 1 \mathrm{c}$ within each practice.

$\mathrm{HbA1c}$, glycated haemoglobin; SEIFA, Socio-Economic Indexes for Areas.

of multimorbidity and LTCs identified in our study align with a recent study that explored multimorbidity in T2D using community cohorts in the UK and Taiwan. ${ }^{6}$ This supports the validity of the NPS MedicineInsight dataset in capturing LTC prevalence in the community. Limitations also exist in regards to the current infrastructure and standards of EHRs. Currently, there are still no nationally agreed and implemented standards for the EHR, particularly for data structure, universally accepted systems of classification and terminology, and consistent data items with clear definitions. ${ }^{35}$ Furthermore, there is no minimum requirement for the types of patient data that should be collected at every patient consultation that could form a standardised minimum dataset. Although these limitations are highlighted, they also pose as important findings. With the increasing interest and use of routinely collected data in research, quality improvement and data evaluation, our study highlights important issues of data quality that must be addressed in the future. Datasets using routinely collected data will need further validation and perhaps data linkage through combination with other data sources, could enhance their value in research studies.

While our current study did not specifically explore mortality, our results suggest that there is a need for future research to examine other factors independent of $\mathrm{HbAlc}$ that contribute to the increased mortality seen in people with multimorbidity and $\mathrm{T}_{2} \mathrm{D}^{14}$ and investigate how people with T2D and their health professionals approach glycaemic management and targets in the context of multimorbidity. Patient-reported outcome measures such as quality of life, patient reported health and function may also be important to consider, however, these are not incorporated in the EHR. Linkage of MedicineInsight data to hospital and mortality datasets to explore health outcomes for people with multimorbidity and T2D is warranted. Improving our understanding of the biology or healthcare delivery approaches that are contributing to the effects of multimorbidity may benefit clinicians in tailoring care for the needs of this complex population of people with T2D. Gaining a greater understanding of the implications of different patterns of multimorbidity will also be important.

\section{CONCLUSION}

In approximately 70000 people with T2D in Australian general practice, we have demonstrated that most people $(>90 \%)$ with T2D live with multimorbidity and that for over $80 \%$ the comorbidity was discordant in nature. Importantly while hypertension was the most common LTC, painful conditions was the second most common LTC. We have found no evidence to support any associations between EHR different patterns or counts of multimorbidity and HbAlc. While it is important for clinicians to consider the impact of multimorbidity in people with T2D, the reasons for the increased mortality observed elsewhere remain unclear and at present are not clearly linked to HbAlc. Our study demonstrates the use of routinely collected real-world clinical data in research, and highlights opportunities to enhance its value in the study of multimorbidity. Better understanding of the implications of multimorbidity in people with T2D, for example, focusing on the importance of common comorbid conditions such as painful conditions will allow more effective tailored care for people with T2D.

Twitter Frances Mair @FrancesMair, Bhautesh D Jani @bhauteshjani, Barbara I Nicholl @BarbNicholl and Jo-Anne Manski-Nankervis@jo_manski

Contributors JC, JF, FM, BJ, BIN, ST and JMN contributed to the study protocol. JC, JF, FM, BJ, BIN, ST and JMN contributed to the study design. JC analysed the data and drafted the initial draft of the manuscript. JC had full access to all study data, performed all the statistical analyses, and takes responsibility for the integrity of the data and the accuracy of data analyses. All authors assisted with iterative 
drafting of the manuscript and agree with the manuscript results and conclusions. All authors read and approved the final manuscript.

Funding This work was supported by the Royal Australian College of General Practitioners Family Medical Care Education and Research (FMCER) Grant 2017 (FMC17a 565484).

Competing interests None declared.

Patient consent for publication Not required.

Ethics approval Ethics approval for this study was obtained from the Human Research Ethics Committee at the University of Melbourne (Ethics ID 1759587). Data access was approved by the independent Data Governance Committee for Medicinelnsight (Ref: 002-2015)

Provenance and peer review Not commissioned; externally peer reviewed.

Data availability statement All data relevant to the study are included in the article or uploaded as online supplemental information.

Supplemental material This content has been supplied by the author(s). It has not been vetted by BMJ Publishing Group Limited (BMJ) and may not have been peer-reviewed. Any opinions or recommendations discussed are solely those of the author(s) and are not endorsed by BMJ. BMJ disclaims all liability and responsibility arising from any reliance placed on the content. Where the content includes any translated material, BMJ does not warrant the accuracy and reliability of the translations (including but not limited to local regulations, clinical guidelines, terminology, drug names and drug dosages), and is not responsible for any error and/or omissions arising from translation and adaptation or otherwise.

Open access This is an open access article distributed in accordance with the Creative Commons Attribution Non Commercial (CC BY-NC 4.0) license, which permits others to distribute, remix, adapt, build upon this work non-commercially, and license their derivative works on different terms, provided the original work is properly cited, appropriate credit is given, any changes made indicated, and the use is non-commercial. See: http://creativecommons.org/licenses/by-nc/4.0/.

\section{ORCID iDs}

Jason I Chiang http://orcid.org/0000-0002-4370-8063

John Furler http://orcid.org/0000-0003-0339-5848

Jo-Anne Manski-Nankervis http://orcid.org/0000-0003-2153-3482

\section{REFERENCES}

1 International Diabetes Federation. IDF diabetes atlas. 8th edn, 2017.

2 Barnett K, Mercer SW, Norbury M, et al. Epidemiology of multimorbidity and implications for health care, research, and medical education: a cross-sectional study. Lancet 2012;380:37-43.

3 Smith SM, Ferede A, O'Dowd T. Multimorbidity in younger deprived patients: an exploratory study of research and service implications in general practice. BMC Fam Pract 2008;9:6.

4 Australian Bureau of Statistics. National health survey: first result, 2015: 2014-5.

5 Mair FS, May CR. Thinking about the burden of treatment. BMJ 2014;349:96680.

6 Chiang JI, Hanlon P, Li T-C, et al. Multimorbidity, mortality, and $\mathrm{HbA1c}$ in type 2 diabetes: a cohort study with UK and Taiwanese cohorts. PLOS Med 2020;17:e1003094.

7 Harris MF, Dennis S, Pillay M. Multimorbidity: negotiating priorities and making progress. Aust Fam Physician 2013;42:850-4.

8 Piette JD, Kerr EA. The impact of comorbid chronic conditions on diabetes care. Diabetes Care 2006;29:725-31.

9 UK Prospective Diabetes Study Group. Intensive blood-glucose control with sulphonylureas or insulin compared with conventional treatment and risk of complications in patients with type 2 diabetes (UKPDS 33). UK prospective diabetes study (UKPDS) group. Lancet 1998;352:837-53.

10 UK Prospective Diabetes Study Group. Effect of intensive bloodglucose control with metformin on complications in overweight patients with type 2 diabetes (UKPDS 34). UK prospective diabetes study (UKPDS) group. Lancet 1998;352:854-65.

11 UK Prospective Diabetes Study Group. Tight blood pressure control and risk of macrovascular and microvascular complications in type
2 diabetes: UKPDS 38. UK prospective diabetes Study Group. BMJ 1998;317:703-13.

12 UK Prospective Diabetes Study Group. Efficacy of atenolol and captopril in reducing risk of macrovascular and microvascular complications in type 2 diabetes: UKPDS 39. UK prospective diabetes Study Group. BMJ 1998;317:713-20.

13 Stratton IM, Adler AI, Neil HA, et al. Association of glycaemia with macrovascular and microvascular complications of type 2 diabetes (UKPDS 35): prospective observational study. BMJ 2000;321:405-12.

14 Chiang JI, Jani BD, Mair FS, et al. Associations between multimorbidity, all-cause mortality and glycaemia in people with type 2 diabetes: a systematic review. PLoS One 2018;13:e0209585.

15 Chiang JI, Furler J, Mair FS, et al. Impact of multimorbidity count on all-cause mortality and glycaemic outcomes in people with type 2 diabetes: a systematic review protocol. BMJ Open 2018;8:e021100.

16 The Academy of Medical Sciences. Multimorbidity: a priority for global health research. Available: https://acmedsci.ac.uk/policy/ policy-projects/multimorbidity

17 Harrison C, Henderson J, Miller G, et al. The prevalence of complex multimorbidity in Australia. Aust N Z J Public Health 2016;40:239-44.

18 RACGP. General practice management of type 2 diabetes: 2016-18. East Melbourne, VIC: RACGP, 2016.

19 Busingye D, Gianacas C, Pollack A, et al. Data resource profile: Medicinelnsight, an Australian National primary health care database. Int J Epidemiol 2019;48:1741-h.

20 RACGP. Standards for general practices. 4th edn, 2015.

21 Jani BD, Hanlon P, Nicholl BI, et al. Relationship between multimorbidity, demographic factors and mortality: findings from the UK Biobank cohort. BMC Med 2019;17:74.

22 Royal College of Pathologists of Australasia (RCPA). LOINC APUTS chemical pathology terminology value set (v2.1) and LOINC APUTS haematology terminology value set (v2.0), 2016. Available: https:// www.nehta.gov.au/implementation-resources/terminology-access

23 Australian Healthcare Messaging. AUSTPATH (Australian pathology code set), 2005. Available: http://www.ahml.com.au/austpath.php

24 Manski-Nankervis J-A, Thuraisingam S, Sluggett JK, et al. Prescribing of diabetes medications to people with type 2 diabetes and chronic kidney disease: a national cross-sectional study. BMC Fam Pract 2019;20:29.

25 Australian Bureau of Statistics (ABS). Census of population and housing: socio-economic indexes for areas (SEIFA), Australia, 2011. Australian Bureau of Statistics, 2013. http://www.abs.gov.au/ ausstats/abs@.nsf/DetailsPage/2033.0.55.0012011?OpenDocument

26 Cheung NW, Conn JJ, d'Emden MC, et al. Position statement of the Australian diabetes Society: individualisation of glycated haemoglobin targets for adults with diabetes mellitus. Med J Aust 2009;191:339-44.

27 Guiding principles for the care of older adults with multimorbidity: an approach for clinicians. Guiding principles for the care of older adults with multimorbidity: an approach for C. guiding principles for the care of older adults with multimorbidity: an approach for clinicians: American geriatrics Society expert panel on the care of older adults with multimorbidity. J Am Geriatr Soc 2012;60:E1-25.

28 Boult C, Wieland GD. Comprehensive primary care for older patients with multiple chronic conditions: "Nobody rushes you through". JAMA 2010;304:1936-43.

29 Noël PH, Parchman ML, Williams JW, et al. The challenges of multimorbidity from the patient perspective. $J$ Gen Intern Med 2007;22:419-24.

30 Holman RR, Paul SK, Bethel MA, et al. 10-Year follow-up of intensive glucose control in type 2 diabetes. N Engl J Med 2008;359:1577-89.

31 Luijks $\mathrm{H}$, Schermer T, Bor $\mathrm{H}$, et al. Prevalence and incidence density rates of chronic comorbidity in type 2 diabetes patients: an exploratory cohort study. BMC Med 2012;10:128.

32 Higashi T, Wenger NS, Adams JL, et al. Relationship between number of medical conditions and quality of care. $N$ Engl $J$ Med 2007;356:2496-504.

33 NPS MedicineWise. General practice insights report July 2016-June 2017: a working paper. 2018. Sydney, Australia: NPS MedicineWise.

34 Britt $\mathrm{H}$, Miller GC, Henderson J, et al. General practice activity in Australia 2015-16. general practice series no40. Sydney, Australia: Sydney University Press, 2016.

35 Deeble Institute Issues Brief No 18. Reality check - reliable national data from general practice electronic health records. Australia: Deeble Institute, 2016. 